\title{
Decision Making for Managing Community Flood Risks: Perspectives of United States Floodplain Managers
}

\author{
Jenna Tyler ${ }^{1} \cdot$ Abdul-Akeem Sadiq $^{1} \cdot$ Douglas S. Noonan $^{2} \cdot$ Rebecca M. Entress $^{1}$
}

Accepted: 4 May 2021 / Published online: 23 September 2021

(C) The Author(s) 2021

\begin{abstract}
To reduce flood losses, floodplain managers make decisions on how to effectively manage their community's flood risks. While there is a growing body of research that examines how individuals and households make decisions to manage their flood risks, far less attention has been directed at understanding the decision-making processes for flood management at the community level. This study aimed to narrow this research gap by examining floodplain managers' perceptions of the quality of their community's flood management decision-making processes. Data gathered from interviews with 200 floodplain managers in the United States indicate that most floodplain managers perceive their community's flood management decision-making processes to be good. The results also indicate that communities participating in the Federal Emergency Management Agency's Community Rating System, as well as communities with a higher level of concern for flooding and a lower poverty rate, are significantly more likely to report better flood management decision-making processes.
\end{abstract}

Keywords Community flood risk management · Decision making · Floodplain managers $\cdot$ United States

Jenna Tyler

jentyler@knights.ucf.edu

1 School of Public Administration, University of Central Florida, Orlando, FL 32801, USA

2 O'Neill School of Public and Environmental Affairs, Indiana University-Purdue University Indianapolis, Indianapolis, IN 46202, USA

\section{Introduction}

Every year for the past 30 years (1988-2017), floods have caused, on average, 82 deaths and cost the United States nearly USD 8 billion in damages (National Weather Service 2018). Recent disasters, such as the 2016 Louisiana Floods, Hurricanes Irma and Harvey in 2017, and the 2019 Midwestern Floods, provide tangible evidence of the devastation caused by flooding. To stem flood losses, floodplain managers make decisions on how to effectively manage their community's flood risks. A floodplain manager refers to the individual in a local community who develops, implements, and oversees the community's floodplain management program (Association of State Floodplain Managers 2010). Effective community flood risk management involves accurately delineating flood risks and implementing cost-effective, sustainable, as well as socially and environmentally conscious measures that not only reduce community flood risks but also enhance the community's resilience to future flood disasters (Woodward et al. 2011; Tyler et al. 2019). Resilience generally refers to the ability to respond and quickly bounce back from disruptions like flood disasters (Tyler and Sadiq 2019).

Engaging in effective community flood risk management poses significant challenges, however. This is due to a variety of reasons such as uncertainties associated with the changing climate, including rising sea levels along the coast and increased rainfall in inland communities, as well as increased social vulnerabilities and outdated flood maps and tools (Bouwer 2011; Brody et al. 2011; Woodward et al. 2011; Tyler et al. 2019). In addition, institutional arrangements and political priorities influence community and political support for comprehensive flood risk management (Whatmore 2013). Communities also have 
economic incentives that tend to forgo longer-term risk management for short-term revenue raising or commercial profits (Michel-Kerjan 2010).

How individuals and households make decisions to manage their flood risks has been well researched in the academic sphere (Terpstra and Lindell 2013). But there has been a lack of research on understanding the decisionmaking processes for flood management at the community level. This study narrows this research gap by examining floodplain managers' perceptions of the quality of their community's flood management decision-making processes. Specifically, the authors used data gathered from interviews with 200 floodplain managers in the United States to answer two research questions: (1) What are floodplain managers' perceptions of the quality of their community's flood management decision-making processes? (2) What factors influence floodplain managers' perceptions of the quality of their community's decisionmaking processes?

This study contributes to the theory and practice of floodplain management in two meaningful ways. First, the study used quantitative and qualitative data to describe floodplain managers' perceptions of their community's flood management decision making. The inclusion of qualitative data responds to calls for more qualitative research on community flood risk management (Sadiq et al. 2020). Second, the study employed the Protective Action Decision Model (PADM) to identify the factors that impact floodplain managers' perceptions. By gathering floodplain managers' perceptions, as well as the factors that influence those perceptions, floodplain managers seeking to improve their community's flood management will have a resource for doing so. For example, the results indicate that communities participating in the Federal Emergency Management Agency's Community Rating System (FEMA's CRS) program, as well as communities with a higher level of concern for flooding and a lower poverty rate, are significantly more likely to report better flood management decision-making processes. Hence, floodplain managers seeking to improve their decision-making processes should consider these factors.

The following section provides a brief overview of decision making in the public sector, and outlines the background of community flood risk management in the United States, including current governance structures. It also reviews the literature to identify potential factors that influence decision-making processes. The third section illustrates the methods and data used in this study, and the fourth and fifth sections present and discuss the results. The final section describes the study limitations and outlines an agenda for future research.

\section{Literature Review}

The literature review is organized into three parts. The first part reviews the literature on decision making in the public sector in general, highlighting salient theories that have guided the field to date. The second part focuses on flood risk management governance and outlines the manner in which floodplain management occurs at the federal, state, and local levels. The final section applies a theoretical framework to understand floodplain managers' perceptions of their community's flood management decision making.

\subsection{Decision Making in the Public Sector}

Literature on decision making in the public sector has historically borrowed from and expanded on rational choice theory (Smith and Larimer 2013). This theory asserts that policymakers and public managers are able to consider all of the information provided and select the most preferred and rational decision to achieve the desired objectives (Frederickson et al. 2016). Recognizing the limitations associated with this theory, Simon (1972) introduced the notion of bounded rationality. Unlike rational choice theory, this theory asserts that individuals satisfice, meaning individuals do not seek to maximize their benefits, but aim to do what is "good enough." Similar to Simon's arguments, Lindblom (1959) argued that decisions are not made all at once, but instead are made incrementally or as Lindblom puts it, by "muddling through." According to Smith and Larimer (2013), policymakers and practitioners tend to prefer incremental changes to highly unfamiliar changes or to societal issues that require large and intricate solutions. Despite being over half a century old, these theories persist today and are relevant to the discussion on floodplain management. Consistent with these theories floodplain managers satisfice when it comes to making decisions on how best to manage flood risks. Moreover, policies regarding floodplain management are developed and implemented incrementally, especially those aimed at addressing climate change impacts.

\subsection{Flood Risk Management Governance}

In the United States, floodplain management is a function at the federal, state, and local levels. Local governments hold most of the flood management and flood regulation responsibilities, state governments act as intermediaries between the federal and local governments, and the federal government primarily focuses on developing high-level policies to address flood risks (Galloway 2008). Local governments develop, implement, and oversee community 
floodplain management programs and regulate development in flood-prone areas (Association of State Floodplain Managers 2010; FEMA 2013). There are several requirements for local communities that participate in the National Flood Insurance Program (NFIP) (FEMA 2013). These communities, for example, have a designated floodplain manager who oversees floodplain management requirements, determines whether proposed developments are in Special Flood Hazard Areas (SFHAs) (areas with a $1 \%$ chance of flooding in any given year), and makes floodplain permitting and development decisions. Local governments assist in preparing and revising floodplain maps and maintaining records for permits, inspections, and enforcement actions. Currently, roughly 22,000 communities participate in the NFIP (FEMA 2017). The local governments also have primary responsibility to inform residents of floodplain hazards and determine whether building improvements are significant enough to meet permit and compliance requirements (FEMA 2013).

State governments are less involved in floodplain management, but still play an important role. The NFIP State Coordinating Agency is the organizational home for the state floodplain managers who serve as a liaison between local and federal flood management offices. State governors are responsible for designating an agency to serve as the NFIP State Coordinating Agency (FEMA 2013). State floodplain managers have a broad statewide focus and serve a function similar to that of local floodplain managers. The state floodplain managers work with local governments to encourage NFIP participation and offer support and technical assistance to communities (FEMA 2013). They also assist in defining flood-prone areas, notifying FEMA of any problems with communities, and support local communities in their own floodplain management regulations, from development to implementation (FEMA 2013).

The federal government has macro-level responsibilities for floodplain management. Federal floodplain managers set flood management policy and manage the NFIP as well as other programs aimed at reducing flood losses. The federal floodplain managers operate primarily within the Federal Insurance and Mitigation Administration (FIMA) at FEMA. Their duties include implementing the NFIP, which consists of flood hazard identification, floodplain management, and flood insurance, among other responsibilities (FEMA 2013). FEMA has 10 regional offices that are responsible for helping NFIP State Coordinating Agencies, advising local floodplain managers, and assessing community compliance with the NFIP (FEMA 2013). The floodplain managers who operate within these 10 regions provide information and training, and work with states and communities to resolve any issues occurring at the local level, revising flood hazard maps, and answering questions and providing information about flood insurance (FEMA 2013).

This study focused on local floodplain managers in the United States by examining their perceptions of the quality of their community's flood management decision-making processes. To do so, we applied the main tenets of Terpstra and Lindell's (2013) Protective Action Decision Model (PADM), which remains a common decision-making tool within the disaster management literature.

\subsection{Applying the Protective Action Decision Model (PADM)}

PADM is a framework used for understanding protective human behavior and decision making during a disaster or threatening event (Strahan and Watson 2019; Liddle et al. 2020). The model was originally developed to understand how people take protective actions when confronted with environmental threats, but it has recently been applied more broadly to understand how people respond to risks in multiple contexts (Liu et al. 2019). At the core of the PADM, hazard-related and resource-related attributes impact decisions and behavior in anticipation of disasters (Terpstra and Lindell 2013). Whereas hazard-related attributes include the perceived efficacy of protecting people and property and "describe the relationship between the hazard adjustment and the hazard" (Terpstra and Lindell 2013, p. 996), resource-related attributes consist of the perceived requirements for resources (for example, time, money, knowledge, and so on) and "describe the relationship between the hazard adjustment and the household's resources" (Terpstra and Lindell 2013, p. 996). According to the PADM, a greater number of hazard-related attributes increases the likelihood of the adoption of protective actions and a greater number of resource-related attributes decrease the likelihood of the adoption of protective actions (Terpstra and Lindell 2013).

More recent developments of the PADM explore decision-making processes in multiple phases, although individuals do not necessarily follow every step in the model sequentially (Lindell and Perry 2012; Heath et al. 2018). Before individuals can take protective action, they must be warned of the risk and understand the information (Lindell and Perry 2012). During the pre-decision stage, people experience exposure, attention, and comprehension and this is influenced by many factors like environmental cues, social cues, and warning messages (Heath et al. 2018). Past tornado warnings, for example, were not understood by people who spoke Spanish since the warning was in English, impeding comprehension and affecting the pre-decision (Lindell and Perry 2012). Following the pre-decision, threat perception, protective action perceptions, and stakeholder perceptions occur simultaneously (Lindell and 
Perry 2012). During this stage, individuals decide whether a real threat exists, the needs for protective actions, and how they are viewing the issue (Strahan and Watson 2019). Theoretically, the perceptions should inform whether and how individuals act when faced with a threat (Heath et al. 2018). Perceptions ultimately inform information search strategies and protective action decision making, which eventually results in a behavioral response (Strahan and Watson 2019). However, once a behavioral response is initiated the process is not over; instead, it loops back to the beginning stages of the PADM (Strahan and Watson 2019). These cycles continue until individuals have enough information to make protective action decisions (Strahan and Watson 2019).

The PADM has been applied to a variety of hazards and in a number of contexts. Lindell and Prater (2002), for example, applied the PADM to examine individuals' adoption of seismic hazard adjustments in Southern California and Western Washington. Data gathered from 561 individuals revealed that hazard-related attributes are significantly related to seismic hazard adjustments adoption; no significant relationship was found between resourcerelated attributes and seismic hazard adjustments adoption (Lindell and Prater 2002). Ge et al. (2011) used the PADM to predict intentions to adopt hurricane mitigation measures among Florida households. The results of this study indicate that the adoption of hurricane mitigation measures was strongly related to hazard intrusiveness (that is, how often hurricanes and hurricane safety are discussed and how often people think of these issues) and the perceived hurricane risk. The results also indicated that worry was significantly related to the adoption of hurricane mitigation measures, albeit to a lesser extent. Scholars have also applied the PADM specifically to the field of flood risk management. Terpstra and Lindell (2013), for example, used data gathered from more than 1,000 individuals to explore intentions to adopt flood preparedness measures. In line with the PADM, the authors found a positive relationship between hazard-related attributes and the intention to adopt flood preparedness measures (Terpstra and Lindell 2013). Their results did not, however, reveal a negative relationship between resource-related attributes and the intention to adopt flood preparedness measures.

While the PADM historically is focused on householders' decision-making processes, we used the model in this study as a framework for understanding perceptions of the quality of flood management decision making. We did not aim to empirically test the validity of the PADM, but rather applied the main tenets of the theory to understand the factors that influence floodplain managers' perceptions.
Applying household disaster-related theories to other units, such as organizations or communities, is common (Tyler et al. 2020).

We contend that hazard- and resource-related attributes will influence floodplain managers' perceptions of the quality of their decision making. We examined two hazardrelated attributes-perceptions of flood concern and flood problems-and three resource-related attributes-employee tenure, number of full-time employees, and participation in FEMA's Community Rating System (CRS) program. Whereas employee tenure is measured at the individual level, the number of full-time employees is measured at the organizational level. FEMA's CRS program is a voluntary flood risk management program implemented in 1990 as a way to incentivize communities to engage in more flood mitigation measures. As communities adopt these measures, they obtain credit points, which in turn allow community members to receive discounted flood insurance premiums. We included participation in FEMA's CRS program as an example of resource-related attribute because studies have consistently shown that communities with more resources are significantly more likely to participate in the program (Tyler et al. 2020). Part of the benefit of participation in the CRS is access to resources (for example, expertise from FEMA and CRS User Groups) (Posey 2009; Sadiq and Noonan 2015; Sadiq et al. 2020).

In line with the PADM, we suggest that there is a positive relationship between floodplain managers' perceptions of their community's level of concern for flooding, as well as the extent to which flooding is a problem in their community, and their perceptions of the quality of their decision-making processes. We also posit that there is a relationship between resource-related attributes and floodplain managers' perceptions. Specifically, we hypothesize that employee tenure, number of full-time employees, and CRS participation will influence floodplain managers' perceptions. Given the inconsistent findings in regard to resource-related variables, we do not specify the direction of the relationship. Based on the ongoing discussion, this study specifically tested two hypotheses:

Hypothesis 1 Floodplain managers' perceptions of flood concern and flood problems are positively and significantly related to perceptions of the quality of flood management decision-making processes.

Hypothesis 2 Employee tenure, number of full-time employees, and CRS participation are significantly related to floodplain managers' perceptions of the quality of flood management decision-making processes. 


\section{Data and Methods}

The data for this study were generated from interviews conducted with floodplain managers in 200 communities from October 2018 to August 2019. The primary purpose of these interviews was to understand the factors and motivations for participating or not participating in FEMA's CRS program. Understanding decision-making processes was a secondary purpose. The following subsections outline the methods used to identify the 200 NFIP communities, the questionnaire and interview protocol, and the variable measurement. The unit of analysis was the community, and the unit of observation was the floodplain manager for each community.

\subsection{Matching Procedure}

This study used data from 200 NFIP communities in the United States, which were matched based on whether they participate in FEMA's CRS program. The data were drawn from one hundred communities that participated in the CRS, and one hundred communities that did not participate. To be included in the sample of CRS communities, a community had to have been listed as a participating community in 2013 (CRS13 = 1) and have observed values for all covariates. Covariates used in this study include flood risk and socioeconomic variables. The study included five flood risk variables: (1) the flood damage in 2012; (2) the county-level flood event damage from the Spatial Hazard Events and Loss Database for the United States (SHELDUS) for 2007-2012; (3) the average flood risk for the county; (4) a dummy variable indicating whether the community had a digital Flood Insurance Rate Map available in 2013; and (5) the population-weighted flood risk for the county. The study also included 11 socioeconomic variables from the 2010 Census: (1) population density; (2) proportion of the population that is White; (3) proportion of the population aged 18 and older; (4) proportion of the population under age 5; (5) proportion of the population with at least a college degree; (6) proportion of the households that lived in the same county 5 years prior; (7) $\log$ of the median housing value (mean of the tract-level medians); (8) proportion of the population below the poverty level; (9) log of the median family income; (10) $\log$ of the aggregate housing value; and (11) share of the housing units that are rented. Our analysis revealed that 1169 out of the 1172 communities in the CRS had data on all observed covariates.

The research team used a sample of 21,804 communities that are eligible to participate in the CRS and used propensity score matching (PSM) to identify the 100 nonCRS matches. To identify matches, we generated propensity scores for each observation. Following this step, we identified the four nearest neighbors for all 100 nonCRS matches. The research team used this matching procedure to ensure that each pair of observations are as identical as possible regarding their probability of participating in the CRS. Matches can be county-to-county, cityto-city, county-to-city, or city-to-county.

\subsection{Questionnaire and Interview Process}

After the $100 \mathrm{CRS}$ and 100 non-CRS matches were identified, the research team designed and pre-tested interview scripts for both groups. The two interview scripts were designed to gather a host of demographic, organizational, and community capacity data, as well as perceptions of flood management decision making, among others. The scripts also contained questions about why a respondent's community does or does not participate in the CRS. Once the interview scripts were finalized, the research team gave them to a university-based social science research institute located in the United States. This research institute conducted the interviews with floodplain managers in all 200 communities by phone. Floodplain managers were identified using lists provided by state mitigation officers and by looking through local community websites. The research institute confirmed that the individual listed served as the floodplain manager before beginning the interview. The interviews began in October of 2018 and all 200 interviews were completed by August 2019. On average, each phone interview lasted 20 minutes. This study was approved by the institutional review board and respondents were assured of confidentiality before participating in the study.

\subsection{Variable Measurement}

The dependent variable is perceptions of decision making, and was measured by the survey question, "Please, rate the decision-making process for flood management in your community on a scale of 1 (poor) to 5 (excellent). Explain your answer briefly." We employed inductive coding techniques to analyze the explanations. This means that we identified themes based on the data (Ravitch and Mittenfelner Carl 2016). The purpose of having respondents explain their answer was to understand why they selected the response they did. To ensure intercoder reliability, two of the authors reviewed each statement and independently identified themes (intercoder reliability score $=0.77$ ). These two individuals then met to review each theme and establish consensus on the final set of themes.

This study also used five primary independent variables that are broken into two categories associated with the PADM-hazard-related variables and resource-related variables, as well as a series of individual and community 
Table 1 Variable measurement in the study on decision making for managing community flood risks in the United States

\begin{tabular}{|c|c|c|}
\hline Variables & Measurement & Source \\
\hline \multicolumn{3}{|l|}{ Dependent variable } \\
\hline $\begin{array}{l}\text { Perception of decision } \\
\text { making }\end{array}$ & $\begin{array}{l}\text { Please, rate the decision-making process for flood management in your } \\
\text { community on a scale of } 1 \text { (poor) to } 5 \text { (excellent). Explain your answer briefly }\end{array}$ & Survey \\
\hline \multicolumn{3}{|l|}{$\begin{array}{l}\text { Hazard-related } \\
\text { independent } \\
\text { variables }\end{array}$} \\
\hline Flood problem & $\begin{array}{l}\text { Please, rate the extent to which flooding is a problem in your community on a } \\
\text { scale of } 1 \text { (not a problem) to } 5 \text { (a major problem) }\end{array}$ & Survey \\
\hline Flood concern & $\begin{array}{l}\text { Please, rate your community's concern for floods on a scale of } 1 \text { (not at all } \\
\text { concerned) to } 5 \text { (extremely concerned) }\end{array}$ & Survey \\
\hline \multicolumn{3}{|l|}{$\begin{array}{l}\text { Resource-related } \\
\text { independent } \\
\text { variables }\end{array}$} \\
\hline Tenure & How long have you been in this position? & Survey \\
\hline Full-time employees & How many full-time employees does your department have? & Survey \\
\hline CRS participation & Coded by authors $(0=$ Non-CRS community, $1=$ CRS community $)$ & Survey \\
\hline \multicolumn{3}{|l|}{ Control variables } \\
\hline Education & What is the highest level of education you have completed? & Survey \\
\hline Gender & What is your gender? & Survey \\
\hline \multicolumn{3}{|l|}{$\begin{array}{l}\text { Community } \\
\text { characteristics }\end{array}$} \\
\hline Population & All people living in a given geographic area & $\begin{array}{l}\text { US Census-2018 American } \\
\text { Community Survey 5-year } \\
\text { estimates }\end{array}$ \\
\hline $\begin{array}{l}\text { Median household } \\
\text { income }\end{array}$ & $\begin{array}{l}\text { The midpoint income for all individuals } 15 \text { years old and over in the household, } \\
\text { with one-half of the cases below the median income and one-half above the } \\
\text { median income }\end{array}$ & $\begin{array}{l}\text { US Census-2018 American } \\
\text { Community Survey 5-year } \\
\text { estimates }\end{array}$ \\
\hline Employment rate & $\begin{array}{l}\text { Percent of individuals in the labor force with paid employment, based on the } \\
\text { week before responding to the census questionnaire }\end{array}$ & $\begin{array}{l}\text { US Census-2018 American } \\
\text { Community Survey 5-year } \\
\text { estimates }\end{array}$ \\
\hline Poverty rate & Percent of individuals living in poverty, based on income in the past 12 months & $\begin{array}{l}\text { US Census-2018 American } \\
\text { Community Survey 5-year } \\
\text { estimates }\end{array}$ \\
\hline Median age & $\begin{array}{l}\text { The age at the midpoint of the population, where half of the population is older } \\
\text { than the median and half is younger }\end{array}$ & $\begin{array}{l}\text { US Census-2018 American } \\
\text { Community Survey 5-year } \\
\text { estimates }\end{array}$ \\
\hline $\begin{array}{l}\text { Percent of individuals } \\
\text { who are white }\end{array}$ & $\begin{array}{l}\text { The percent of the population with origins in any of the original peoples of } \\
\text { Europe, the Middle East, or North Africa, including people who indicate their } \\
\text { race as "White" or report entries such as Irish, German, Italian, Lebanese, } \\
\text { Arab, Moroccan, or Caucasian }\end{array}$ & $\begin{array}{l}\text { US Census-2018 American } \\
\text { Community Survey 5-year } \\
\text { estimates }\end{array}$ \\
\hline $\begin{array}{l}\text { Percent of individuals } \\
\text { with a disability }\end{array}$ & $\begin{array}{l}\text { Percent of the population with serious difficulty with hearing, vision, cognition, } \\
\text { and ambulation }\end{array}$ & $\begin{array}{l}\text { US Census-2018 American } \\
\text { Community Survey 5-year } \\
\text { estimates }\end{array}$ \\
\hline
\end{tabular}

characteristics as control variables. Table 1 provides a summary of how all the variables were measured.

\section{Results}

The majority of the responding floodplain managers were male $(72.5 \%)$, over the age of $44(66.5 \%)$, and held a bachelor's $(46 \%)$ or graduate degree (33\%). Most respondents had been in their position for approximately 3 to 8 years $(38 \%)$. Table 2 presents the sample statistics for all floodplain managers.

Figure 1 shows the percentage of respondents that perceived their community's flood management decisionmaking processes as excellent, good, fair, or poor: $57.4 \%$ $(\mathrm{n}=112)$ of respondents reported their decision-making process as good; $31.3 \%(n=61)$ thought it to be excellent; 
Table 2 Sample statistics of the 200 floodplain managers in the study on decision making for managing community flood risks in the United States

\begin{tabular}{ll}
\hline Variables & Floodplain managers (\%) \\
\hline Gender & $145(72.5)$ \\
Male & $55(27.5)$ \\
Female & \\
Age & $58(29.0)$ \\
$27-44$ & $86(43.0)$ \\
$45-59$ & $47(23.5)$ \\
$60+$ & $8(0.4)$ \\
No response & \\
Education & $6(3.0)$ \\
High school & $19(9.5)$ \\
Some college or technical school & $17(8.5)$ \\
2-Year college degree & $92(46.0)$ \\
Bachelor's degree & $66(33.0)$ \\
Graduate degree & \\
Tenure & $39(19.5)$ \\
Less than 3 years & $76(38.0)$ \\
3-8 years & $42(21.0)$ \\
9-14 years & $14(7.0)$ \\
15-20 years & $25(12.5)$ \\
Over 20 years &
\end{tabular}

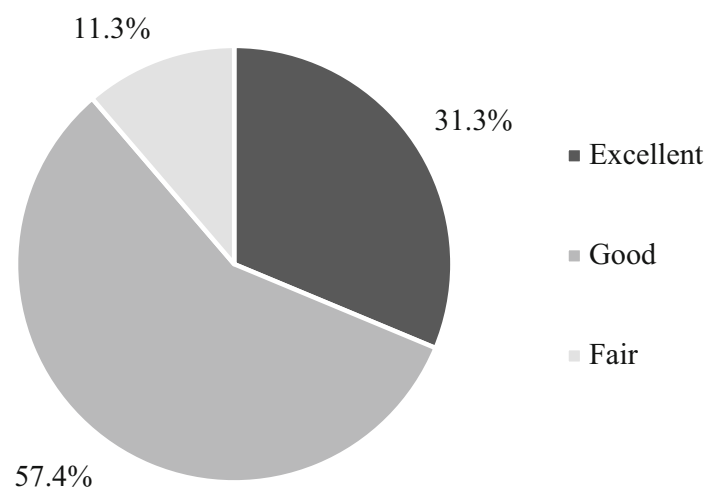

Fig. 1. Floodplain managers' perceptions of the quality of their community's flood management decision making

and $11.3 \%(n=22)$ judged it to be fair. No respondents reported their decision-making processes to be poor.

\subsection{Excellent Decision Making}

Among the respondents reporting excellent decision making, 21 cited the floodplain ordinance, standard, or regulation as the reason that their decision-making process was excellent (Table 3). Respondents stressed both that the ordinances, standards, or regulations were strong, and also
Table 3 Summary of reasons floodplain managers rated their community decision making as excellent, good, or fair

Code N N

Excellent decision making

Floodplain ordinances, standards, or regulations 21

CRS rating and/or participation 8

Public participation, education, and/or outreach 7

Collaboration 6

Community composition 6

Restricting floodplain development 6

Government support and/or direction 5

Proactive approach 5

High flood risk 3

Lack of floods and/or floodplains 3

Floodplain maps and data 3

Have funding 3

Other 23

Good decision making

Floodplain management 24

Enforcing and/or complying with rules and regulations 17

Floodplain ordinances, standards, or regulations 13

Lack of floods and/or few flood issues 10

Coordination and/or collaboration $\quad 8$

Availability of resources $\quad 7$

$\begin{array}{ll}\text { Education and/or outreach } & 7\end{array}$

Improvements $\quad 7$

$\begin{array}{ll}\text { Knowledge and/or understanding } & 7\end{array}$

Presence of floodplain $\quad 7$

Review 6

CRS participation and/or rating 5

Maps 5

Planning, prevention, and/or mitigation 5

Political support 5

Proactive approach 5

Community composition 4

Other 55

Fair decision making

Improvements and recognition for improvements 5

Floodplain ordinances, standards, or regulations 4

Lack of resources 4

Floodplain maps 3

Community composition 2

Other 19

that they were enforced. Eight respondents cited their CRS rating and/or participation in the CRS as the reason for excellent decision making. Specifically, they cited their CRS class rating, the length of time they have been in the CRS program, and the activities required by the CRS 
program as the primary reasons for excellent decision making. Seven respondents cited public participation, education, and/or outreach as the reason for excellent decision making. They noted that the public was educated and involved, including citizens, homebuyers, property owners, and building officials. Twenty-three respondents specified reasons that did not fall into any specific code. These responses were coded as "other." One respondent specified that there was excellent decision making because engineers are in charge, and another specified that they learned from the mistakes of the past. Responses coded as "other" also included reasons such as having funding, floodplain maps and data, and lack of floods and/or floodplains.

\subsection{Good Decision Making}

The most commonly cited reason for good decision making was related to the ability to manage the floodplain and restrict development (24 respondents) (Table 3). Of these, four respondents cited the floodplain ordinance (and noted the ordinance itself was helpful, rather than simply having an ordinance, standard, or regulation), one respondent stated development must meet floodplain requirements, and one respondent stated there is not a lot of redevelopment in the floodplain. Seventeen respondents cited enforcing and/ or complying with rules and regulations as the reason they considered decision making good. This included following and enforcing ordinances, FEMA standards, and federal and state regulations, and the respondents noted that the enforcement was strict and taken seriously. Other commonly cited reasons for good decision making were related to having a floodplain ordinance, standard, and/or regulation (13 respondents), and a lack of floods and/or few flood issues (10 respondents). Similar to excellent decision making, floodplain managers had a wide range of reasons regarding why decision making was good, and 55 floodplain managers cited reasons not shared by other floodplain managers. Such reasons range from having a good relationship with FEMA, not prioritizing the program within the community, and being thorough.

\subsection{Fair Decision Making}

There was little consensus regarding why respondents considered decision making to be fair (Table 3). Five respondents reported improvements and recognition for improvements as the reason that they reported their decision making as fair. These respondents explained that the communities are working towards making improvements and that there is room for improvements. Four respondents reported that their ranking of fair is due to their commu- nity's floodplain ordinances, standards, or regulations. One respondent specifically stated that they are trying to get used to the regulations and one explained that they recently passed a floodplain ordinance to put the community in line with FEMA requirements. Nineteen respondents reported reasons that did not fit within a category and reasons ranged from management turnover, to poor infrastructure, and insufficient floodplain education and understanding. One floodplain manager stated that they do not agree with FEMA's designation of areas in their community that reside in a floodplain, and another said there is significant risk.

Next, we identified the factors that influence floodplain managers' perceptions of the quality of their community's flood management decision-making processes. Table 4 presents the summary statistics for all variables. The average score for the dependent variable, perception of decision making is 4.2 on a scale of one to five. The average scores for the two hazard-related independent variables-flood problem and flood concern-are 2.63 and 3.72 (on a scale of one to five), respectively. With respect to the resource-related variables, on average floodplain managers have been in their position for just under 10 years, and the average number of full-time employees in the department is 35.8. Half of the floodplain managers work in communities that participate in the CRS program.

We conducted Pearson correlations to determine the relationship between all variables (Table 5). Three of the five independent variables are positively and significantly related to perceptions of flood management decision making-flood concern $(p<0.01)$, tenure $(p<0.05)$, and CRS participation $(p<0.01)$. Two control variables are also significant. Median household income is positively related $(p<0.05)$, while the poverty rate is negatively related $(p<0.05)$.

Table 6 presents the results of the ordered logit regression. This model is appropriate as the dependent variable has five categories, ranging from poor to excellent. The likelihood ratio chi-square of 39.39 with a $p$-value of 0.00 indicates the model as a whole is statistically significant, as compared to a null model with no predictors. Similar to the Pearson correlations, flood concern and CRS participation are statistically significant. For a one unit increase in flood concern and in CRS participation, we expect 0.30 and 1.33 increases, respectively, in the log odds of being in a higher level of flood management decision making, holding all other variables constant. Among the control variables, poverty rate is statistically significant and negative as it was in the Pearson correlations. No other control variable, including median household income (significant in the Pearson correlations), is significant. 
Table 4 Summary statistics of the dependent and independent variables in the study on decision making for managing community flood risks in the United States

\begin{tabular}{|c|c|c|c|c|c|}
\hline Variables & Obs. & Mean & SD & Min & Max \\
\hline \multicolumn{6}{|l|}{ Dependent variable } \\
\hline Perception of decision making & 195 & 4.2 & 0.62 & 3 & 5 \\
\hline \multicolumn{6}{|l|}{ Hazard-related independent variables } \\
\hline Flood problem & 192 & 2.63 & 0.76 & 1 & 5 \\
\hline Flood concern & 200 & 3.72 & 1.28 & 1 & 5 \\
\hline \multicolumn{6}{|l|}{ Resource-related independent variables } \\
\hline Tenure & 200 & 9.38 & 8.27 & 0.10 & 40 \\
\hline Full-time employees & 194 & 35.8 & 89.89 & 1 & 700 \\
\hline CRS participation & 200 & 0.50 & 0.50 & 0 & 1 \\
\hline \multicolumn{6}{|l|}{ Control variables } \\
\hline Education & 200 & 3.97 & 1.03 & 0 & 5 \\
\hline Female & 200 & 0.28 & 0.45 & 0 & 1 \\
\hline Population size & 200 & 118,355 & 199,596 & 479 & $1,203,166$ \\
\hline Median household income (USD) & 200 & $60,327.14$ & $21,773.54$ & 20,179 & 209,825 \\
\hline Poverty rate & 200 & 14.32 & 7.30 & 2.1 & 42.20 \\
\hline Employment rate & 200 & 56.81 & 9.61 & 19.2 & 78.50 \\
\hline Median age & 200 & 40.08 & 8.81 & 23.1 & 75.40 \\
\hline Percent of individuals who are white & 200 & 76.75 & 18.03 & 14.6 & 100 \\
\hline Percent of individuals with a disability & 200 & 13.45 & 4.43 & 2.7 & 33.3 \\
\hline
\end{tabular}

\section{Discussion}

This study used data from interviews with 200 floodplain managers in the United States to answer two research questions: (1) What are floodplain managers' perceptions of the quality of their community's flood management decision-making processes? (2) What factors influence floodplain managers' perceptions of the quality of their community's decision-making processes? Overall, floodplain managers reported their community's flood management decision-making process as good. This seems to suggest that floodplain managers perceive their community satisfices when it comes to making flood management decisions, meaning they make decisions that are "good enough."

The qualitative data yield important insights into why floodplain managers selected the response they did. Those citing their flood management decision making as excellent frequently reported their floodplain ordinances, standards, or regulations as the reason that their decision making is excellent. Another reason is their participation in the CRS. This is not particularly surprising as the CRS provides communities with access to more resources such as expertise from FEMA and participation in CRS user groups (Posey 2009). Several studies have established that CRS participation can lead to reduced flood losses (Highfield and Brody 2017) and flood damages (Highfield and Brody 2013). Those who rated their flood management decision making as good generally discussed their community's ability to manage the floodplain and restrict development in flood-prone areas, as well as enforcing and/or complying with rules and regulations. Those that reported their decision-making process as fair discussed the need to make improvements in their flood management processes. No floodplain managers reported their decision-making processes as poor. Although interesting, these findings are not too surprising as the literature suggests that organizational managers and leaders tend to overstate their level of disaster preparedness (Sadiq and Graham 2016; Tyler et al. 2020).

With respect to the factors that influence floodplain managers' perceptions of the quality of their community's decision-making processes, we found that communities that participate in the CRS, as well as communities with a higher level of concern for flooding, are significantly more likely to report better flood management decision-making processes. These findings thus only provide partial support for our two hypotheses-based on the PADM, we hypothesized that there would be a positive relationship between floodplain managers' perceptions of their community's level of concern for flooding, as well as the extent to which flooding is a problem in their community, and 
Table 5 Pearson correlations among all variables in the study on decision making for managing community flood risks in the United States

\begin{tabular}{|c|c|c|c|c|c|c|c|c|c|}
\hline & 1 & 2 & 3 & 4 & 5 & 6 & 7 & 8 & 9 \\
\hline 1. Perception of decision making & 1.00 & & & & & & & & \\
\hline 2. Flood problem & 0.05 & 1.00 & & & & & & & \\
\hline 3. Flood concern & $0.18 * * *$ & $0.57 * * *$ & 1.00 & & & & & & \\
\hline 4. Tenure & $0.15^{* *}$ & -9.05 & 0.02 & 1.00 & & & & & \\
\hline 5. Full-time employees & 0.09 & 0.03 & 0.02 & 0.00 & 1.00 & & & & \\
\hline 6. CRS participation & $0.27 * * *$ & $0.27 * * *$ & $0.25 * * *$ & -0.07 & 0.00 & 1.00 & & & \\
\hline 7. Education & -0.04 & -0.05 & -0.03 & -0.11 & 0.07 & -0.06 & 1.00 & & \\
\hline 8. Female & 0.05 & -0.16 & 0.19 & -0.08 & -0.02 & 0.05 & -0.20 & 1.00 & \\
\hline 9. Population size & -0.00 & $0.22 * * *$ & 0.16 & 0.07 & 0.31 & -0.11 & 0.08 & -0.02 & 1.00 \\
\hline 10. Median household income & $0.15^{* *}$ & -0.08 & -0.03 & 0.11 & 0.04 & 0.00 & 0.06 & -0.08 & 0.02 \\
\hline 11. Poverty rate & $-0.17 * *$ & 0.05 & 0.01 & -0.11 & 0.02 & 0.01 & -0.04 & -0.01 & 0.01 \\
\hline 12. Employment rate & 0.01 & -0.06 & 0.01 & 0.09 & 0.16 & -0.23 & 0.19 & 0.01 & 0.26 \\
\hline 13. Median age & 0.05 & 0.03 & 0.04 & 0.04 & $-0.15^{* *}$ & $0.20 * * *$ & $-0.16 * *$ & 0.11 & $-0.21 * * *$ \\
\hline 14. Percent white & 0.06 & -0.04 & -0.09 & 0.07 & $-0.18 * *$ & 0.10 & -0.02 & 0.00 & -0.32 \\
\hline \multirow[t]{2}{*}{ 15. Percent disability } & -0.10 & 0.06 & 0.01 & -0.02 & $-0.16^{* *}$ & 0.05 & $-0.16^{* *}$ & 0.06 & $-0.19 * * *$ \\
\hline & 10 & & 11 & & 12 & 13 & & 14 & 15 \\
\hline
\end{tabular}

1. Perception of decision making

2. Flood problem

3. Flood concern

4. Tenure

5. Full-time employees

6. CRS participation

7. Education

8. Female

9. Population size

10. Median household income

11. Poverty rate

12. Employment rate

13. Median age

14. Percent white

15. Percent disability
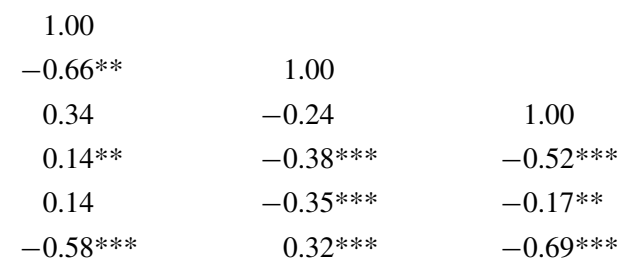

1.00

$0.41 * * * \quad 1.00$

$* p<0.10, * * p<0.05, * * * p<0.01$

their perceptions of the quality of their community's flood management decision-making processes.

The results from the ordered logistic model indicate that only flood concern is positively and significantly related to perceptions of the quality of flood management decisionmaking processes. Moreover, in line with the PADM, we posited that there will be a significant relationship between resource-related attributes and floodplain managers' perceptions of the quality of their community's flood management decision-making processes. Specifically, we hypothesized that employee tenure, number of full-time employees, and CRS participation would significantly influence floodplain managers' perceptions. But the results from the ordered logit model only provide partial support for our assertion. This is because only CRS participation was significantly related to perceptions of the quality of flood management decision-making processes. The positive relationship between CRS participation and the quality of flood management decision making can be explained by previous studies that have found the CRS to be beneficial to communities (Highfield and Brody 2013, 2017). Floodplain managers whose communities are participating in the CRS and enjoying the benefits associated with the CRS are more likely to view their flood management decision making to be excellent in comparison to floodplain managers who are 
Table 6 Ordered logit regression in the study on decision making for managing community flood risks in the United States

\begin{tabular}{ll}
\hline Variable & Coefficient (SE) \\
\hline Flood problem & $-0.17(0.16)$ \\
Flood concern & $0.30 * *(0.15)$ \\
Tenure & $0.04(0.02)$ \\
Full-time employees & $0.00(0.00)$ \\
CRS participation & $1.33 * * *(0.35)$ \\
Education & $0.04(0.15)$ \\
Female & $0.38(0.36)$ \\
Population size & $-3.40 \mathrm{e}-07(8.97 \mathrm{e}-07)$ \\
Median household income & $7.32 \mathrm{e}-06(0.00)$ \\
Poverty rate & $-0.07 *(0.04)$ \\
Employment rate & $-0.02(0.03)$ \\
Median age & $-0.04(0.03)$ \\
Percent of individuals who are white & $0.00(0.01)$ \\
Percent of individuals with a disability & $0.00(0.06)$ \\
$N$ & 188 \\
LR Chi ${ }^{2}$ & 39.39 \\
Prob $>$ Chi ${ }^{2}$ & 0.00 \\
Pseudo $R^{2}$ & 0.11 \\
\hline
\end{tabular}

not enjoying similar benefits, perhaps because their community is not participating in the CRS.

\section{Conclusion}

While the study findings are helpful, they are nascent and further research is needed. A starting place would be to build on the three limitations of this study. The first limitation is that the information from floodplain managers is based on their perceptions, which may not reflect the reality. Previous studies suggest that individuals are likely to inflate their level of preparedness (Sadiq and Graham 2016; Tyler et al. 2020). We have no reason to believe floodplain managers are any different. Hence, before the results of this study are applied by policymakers and practitioners, we recommend that future research use objective measures of decision making or develop an objective index to assess the quality of flood management decision-making processes. The second limitation has to do with the small sample size, which makes generalizing our findings a cautionary tale. We suggest that future studies use data from a larger sample of floodplain managers. The third limitation is that the question used to measure the dependent variable is very broad, potentially making it difficult for the respondents to evaluate their decision making. We recommend that future studies use a more narrowly defined measure and explain what they mean by decision making so that respondents have a better way to evaluate their decision making and provide accurate responses. These three limitations notwithstanding, this study provides a good foundation for examining the decision-making process in the context of community flood risk management.

Acknowledgments This article is based on research funded by the US National Science Foundation (NSF) Grant No. 1838421. The findings and opinions are those of the authors and do not necessarily represent the NSF.

Open Access This article is licensed under a Creative Commons Attribution 4.0 International License, which permits use, sharing, adaptation, distribution and reproduction in any medium or format, as long as you give appropriate credit to the original author(s) and the source, provide a link to the Creative Commons licence, and indicate if changes were made. The images or other third party material in this article are included in the article's Creative Commons licence, unless indicated otherwise in a credit line to the material. If material is not included in the article's Creative Commons licence and your intended use is not permitted by statutory regulation or exceeds the permitted use, you will need to obtain permission directly from the copyright holder. To view a copy of this licence, visit http://creativecommons. org/licenses/by/4.0/.

\section{References}

Association of State Floodplain Managers. 2010. Model job description for a community floodplain manager. https://www.floods. org/career-center/careers-in-floodplain-management/sample-posi tion-descriptions/. Accessed 3 Jul 2020.

Bouwer, L.M. 2011. Have disaster losses increased due to anthropogenic climate change?. Bulletin of the American Meteorological Society 92(1): 39-46.

Brody, S.D., J. Gunn, W. Peacock, and W.E. Highfield. 2011. Examining the influence of development patterns on flood damages along the Gulf of Mexico. Journal of Planning Education and Research 31(4): 438-448.

FEMA (Federal Emergency Management Agency). 2013. Substantial improvement/substantial damage desk reference. https://www. fema.gov/sites/default/files/2020-07/fema_nfip_substantialimprovement-substantial-damage-desk-reference.pdf. Accessed 3 Jul 2020.

FEMA (Federal Emergency Management Agency). 2017. National Flood Insurance Program (NFIP) Manual. https://www.fema. gov/flood-insurance/work-with-nfip/manuals/archive. Accessed 23 Aug 2021.

Frederickson, H.G., K.B. Smith, C.W. Larimer, and M.J. Licari. 2016. The public administration theory primer. New York: Routledge.

Galloway, G.E. 2008. Flood risk management in the United States and the impact of Hurricane Katrina. International Journal of River Basin Management 6(4): 301-306.

Ge, Y., W.G. Peacock, and M.K. Lindell. 2011. Florida households' expected responses to hurricane hazard mitigation incentives. Risk Analysis: An International Journal 31(10): 1676-1691.

Heath, R.L., J. Lee, M.J. Palenchar, and L.L. Lemon. 2018. Risk communication emergency response preparedness: Contextual assessment of the protective action decision model. Risk Analysis 38(2): 333-344. 
Highfield, W.E., and S.D. Brody. 2013. Evaluating the effectiveness of local mitigation activities in reducing flood losses. Natural Hazards Review 14(4): 229-236.

Highfield, W.E., and S.D. Brody. 2017. Determining the effects of the FEMA Community Rating System program on flood losses in the United States. International Journal of Disaster Risk Reduction 21: 396-404.

Liddell, J.L., L.Y. Saltzman, R.J. Ferreira, and A.E. Lesen. 2020. Cumulative disaster exposure, gender and the protective action decision model. Progress in Disaster Science 5: Article 100042.

Lindblom, C.E. 1959. The science of "muddling through". Public Administration Review 19(2): 79-88.

Lindell, M.K., and R.W. Perry. 2012. The protective action decision model: Theoretical modifications and additional evidence. Risk Analysis 32(4): 616-632.

Lindell, M.K., and C.S. Prater. 2002. Risk area residents' perceptions and adoption of seismic hazard adjustments. Journal of Applied Social Psychology 32(11): 2377-2392.

Liu, Y., Z. Ouyang, and P. Cheng. 2019. Predicting consumers' adoption of electric vehicles during the city smog crisis: An application of the protective action decision model. Journal of Environmental Psychology 64: 30-38.

Michel-Kerjan, E.O. 2010. Catastrophe economics: The national flood insurance program. Journal of Economic Perspectives 24(4): 165-186.

National Weather Service. 2018. Flood damage/costs/fatalities. https://www.ncdc.noaa.gov/stormevents/. Accessed 3 Jul 2020.

Posey, J. 2009. The determinants of vulnerability and adaptive capacity at the municipal level: Evidence from floodplain management programs in the United States. Global Environmental Change 19(4): 482-493.

Ravitch, S.M., and N. Mittenfelner Carl. 2016. Qualitative research: Bridging the conceptual, theoretical, and methodological. Thousand Oaks, CA: SAGE Publications.

Sadiq, A.A., and J.D. Graham. 2016. Exploring the predictors of organizational preparedness for natural disasters. Risk Analysis 36(5): 1040-1053.
Sadiq, A.A., and D. Noonan. 2015. Local capacity and resilience to flooding: Community responsiveness to the community ratings system program incentives. Natural Hazards 78(2): 1413-1428.

Sadiq, A.A., J. Tyler, D.S. Noonan, R.K. Norton, S.E. Cunniff, and J. Czajkowski. 2020. Review of the Federal Emergency Management Agency's Community Rating System program. Natural Hazards Review 21(1): 1-13.

Simon, H.A. 1972. Theories of bounded rationality. Decision and Organization 1(1): 161-176.

Smith, K.B., and C.W. Larimer. 2013. The public policy theory primer. New York: Routledge.

Strahan, K., and S.J. Watson. 2019. The protective action decision model: When householders choose their protective response to wildfire. Journal of Risk Research 22(12): 1602-1623.

Terpstra, T., and M.K. Lindell. 2013. Citizens' perceptions of flood hazard adjustments: An application of the protective action decision model. Environment and Behavior 45(8): 993-1018.

Tyler, J., and A.A. Sadiq. 2019. The essential skill set of a resilient emergency manager. Journal of Emergency Management 17(1): $35-43$.

Tyler, J., A.A. Sadiq, and G.L. Chikoto-Schultz. 2020. Variations in employees' perceptions of organizational disaster preparedness. Journal of Contingencies and Crisis Management 28(1): 2-18.

Tyler, J., A.A. Sadiq, and D.S. Noonan. 2019. A review of the community flood risk management literature in the USA: Lessons for improving community resilience to floods. Natural Hazards 96(3): 1223-1248.

Whatmore, S.J. 2013. Earthly powers and affective environments: An ontological politics of flood risk. Theory, Culture \& Society 30(7-8): 33-50.

Woodward, M., B. Gouldby, Z. Kapelan, S.T. Khu, and I. Townend. 2011. Real options in flood risk management decision making. Journal of Flood Risk Management 4(4): 339-349. 